\title{
Aplicación de tecnologías de información geográfica para el estudio arqueológico del corredor mesoamericano en el sur de Honduras
}

Rodríguez, César y Rejas Ayuga, Juan Gregorio

\section{Resumen}

En el presente artículo se describe la aplicación de la teledetección espacial y los Sistemas de Información Geográfica (SIG) en una primera aproximación a la investigación arqueológica del corredor mesoamericano a su paso por el sur de Honduras. El área de estudio cubre amplias zonas de los departamentos de Choluteca y Valle, representando un espacio poco investigado de gran relevancia antropológica.

Uno de los objetivos principales del trabajo ha sido el reconocimiento y registro de sitios arqueológicos mediante técnicas no intrusivas, acción necesaria en un estadio inicial para la protección del patrimonio cultural hondureño en la región. Se han utilizado imágenes de los sensores ALI, TM y ETM+ en un período comprendido entre 1990 y 2011, que han sido co-registradas y procesadas para transformarlas a una misma escala radiométrica. Se han aplicado filtros y se han calculado índices que han permitido correlacionar parámetros del suelo y vegetación con la identificación de estructuras arqueológicas. Las muestras de materiales tomadas in situ se han medido en campo y en laboratorio con un espectro radiómetro ASD FieldPro, con el objeto de generar patrones espectrales que faciliten el reconocimiento automático de otros restos arqueológicos homólogos. Los emplazamientos han sido verificados y geo referenciados por posicionamiento global GPS, validando los casos positivos en la cartografía temática generada a partir de las imágenes. Finalmente, se exponen los resultados obtenidos así como los análisis exploratorios iniciados por técnicas SIG para el conocimiento de las relaciones espaciales y geomorfológicas entre los principales asentamientos y culturas pre hispanos en el camino conductor que supone el corredor de Centroamérica.

Palabras clave: Tecnologías de información geográfica. Teledetección espacial. SIG. Prospección arqueológica. Patrimonio cultural. 


\section{Abstract}

This paper describes the application of remote sensing and Geographic Information Systems (GIS) in a first approach to archaeological research Mesoamerican corridor passing through southern Honduras. The study area covers large areas of the departments of Choluteca and Valle, representing an under-researched area of great anthropological importance.

One of the main objectives of this work has been the recognition and recording of archaeological sites using non-intrusive techniques, necessary action at an early stage for the protection of cultural heritage in the region of Honduras. We used images from sensors, ALI, TM and ETM + in a period between 1990 and 2011, which have been co-registered and processed for conversion to a common radiometric scale. Filters have been applied and calculated indices correlate allowed soil and vegetation parameters with identifying archaeological structures. Material samples taken in situ measured in field and laboratory with an ASD field spectroradiometer pro, in order to generate spectral patterns to facilitate automatic recognition of other archaeological remains counterparts. The sites have been checked and georeferenced by GPS global positioning, validating the positive cases in thematic mapping generated from images. Finally, we present the results and exploratory analyzes initiated by GIS techniques for understanding and geomorphological spatial relationships between the main settlements and cultures prehispanos driver on the road representing the Central Corridor.

Keywords: Geographic information technologies. Remote sensing. GIS. Survey archaeological. Cultural heritage.

Rodríguez, César (cesaronca@gmail.com), Facultad de Ciencias Espaciales, Universidad Nacional Autónoma de Honduras, FACES-UNAH. Rejas Ayuga, Juan Gregorio (juangregorio.rejas@upm.es), Depto. de Ingeniería y Morfología del Terreno, Universidad Politécnica de Madrid, UPM. 


\section{INTRODUCCIÓN}

El desarrollo de sensores de observación de la Tierra y Tecnologías de la Información Geográfica (TIG), así como su creciente utilización en arqueología, amplía las posibilidades en la representación y estudio de las características y rasgos particularizados en sitios con presencia de patrimonio arqueológico. En un nivel de estudio inicial, en el que se pretende encontrar indicios de estructuras enterradas y formaciones creadas por el hombre, la respuesta de las superficies en longitudes de onda adecuadas del espectro reflectivo (VIS-SWIR) y emisivo (TIR) puede suponer una información relevante como apoyo en investigación arqueológica.

En el trabajo que se presenta se realiza un aplicación en este sentido, teniendo por objeto reconocer, identificar y registrar digitalmente la ubicación de sitios arqueológicos en los departamentos de Valle y Choluteca en la región sur de Honduras mediante técnicas no intrusivas de teledetección, para posteriormente elaborar un estudio espacial de sus relaciones a partir de Sistemas de Información Geográfica (SIG).

La investigación se ha centrado inicialmente en la aplicación de técnicas de teledetección espacial y tecnologías de información geográfica en prospección y análisis para la extracción de información espectral sobre localización, tipología y estado del patrimonio cultural hondureño, principalmente arqueológico, en esta parte del corredor mesoamericano. Los yacimientos arqueológicos en esta región son casi desconocidos y objeto de saqueo y destrucción, siendo además la información disponible sobre su estado y localización muy escasa. El estudio mediante tecnologías de la información geográfica supone por lo tanto, una primera acción para promover la preservación e investigación arqueológicas en esta zona especialmente desfavorecida.

Se presentan en el artículo los resultados iniciales sobre unas áreas de especial interés, así como la cartografía temática generada. Como objetivo no técni$\mathrm{co}$, se prevé que este trabajo sirva para apoyar la toma de decisiones municipales, locales y regionales desde el IHAH (Instituto Hondureño de Antropología e Historia) en pro de la protección y conservación de nuestro patrimonio cultural en esta región de Honduras. Esta investigación se acoge a la Ley de Protección del Patrimonio Cultural de la Nación. 


\section{DATOS Y ÁREADE ESTUDIO}

\subsection{Zona costera de Choluteca y Valle}

El área de estudio se encuentra situada en la región sur de Honduras y la planicie costera del litoral pacífico, abarcando un total del $2 \%$ del territorio nacional. Tiene una longitud de $133 \mathrm{~km}$ y la cruzan cuatro ríos, siendo estos, de oeste a este el Goascorán, Nacaome, Choluteca y Negro. El de mayor interés para nosotros en este momento y el de mayor caudal es el río Choluteca, formado por cuatro afluentes, que divide las ciudades gemelas de Tegucigalpa y Comayagüela, y que a partir de aquí es conocido como río Choluteca. Sigue rumbo norte, luego se dirige al este y por fin hacia el sur, teniendo una longitud de 250 km (Pineda Portillo 1997: 91).

La planicie costera goza de un clima de sabana, tropical lluvioso y seco, con altas temperaturas todo el año. De seis meses cada una, prevalecen dos estaciones bien marcadas: una de sequía (verano) de noviembre a abril y otra de lluvias (invierno) de mayo a octubre. Del litoral y hasta los $600 \mathrm{msnm}$ hacia el norte, la planicie goza de una vegetación de bosque seco tropical. Se encuentra ubicada en la cadena de volcanes del Cuaternario, que viene desde Guatemala y se extiende hasta Panamá, pasando por el golfo de Fonseca. Las islas (conos) de este golfo son testigo de esa actividad volcánica antigua. El litoral es una unidad fisiográfica de limos y arcilla aluviales, con presencia abundante de manglares.

Se han definido áreas de test como de especial interés (ver Tabla 1), en base a la documentación y revisión bibliográfica realizada. Según Veliz (Véliz 1983; Véliz 2011) se tiene información general transmitida oralmente sobre salineras y la arqueología general de la zona (Baudez 1966) e información concreta sobre la existencia de dos sitios arqueológicos (Stone 1957: 97-98). Uno conocido como La Ola , un poco al noroeste de la ciudad de Choluteca, que se extiende a ambos lados del río Choluteca; el otro sitio conocido como Colama, un poco al suroeste de Choluteca. Ambos presentan tipologías arqueológicas en forma de montículos bajos de tierra y piedra, donde han aparecido vasijas polícromas. 
Tabla 1: Áreas de test de especial interés en la zona de estudio de la tesis

\begin{tabular}{|c|c|c|}
\hline ÁREA DE INTERÉS & NOMBRE & LOCALIZACIÓN \\
\hline AT-1 & Salineras & Choluteca \\
\hline AT-2 & La Ola & Choluteca \\
\hline AT-3 & Colama & Choluteca \\
\hline AT-4 & Isla Amapala & Golfo de Fonseca \\
\hline AT-5 & Isla de Potrerillos & San Lorenzo \\
\hline AT-6 & Camaronera & Valle \\
\hline
\end{tabular}

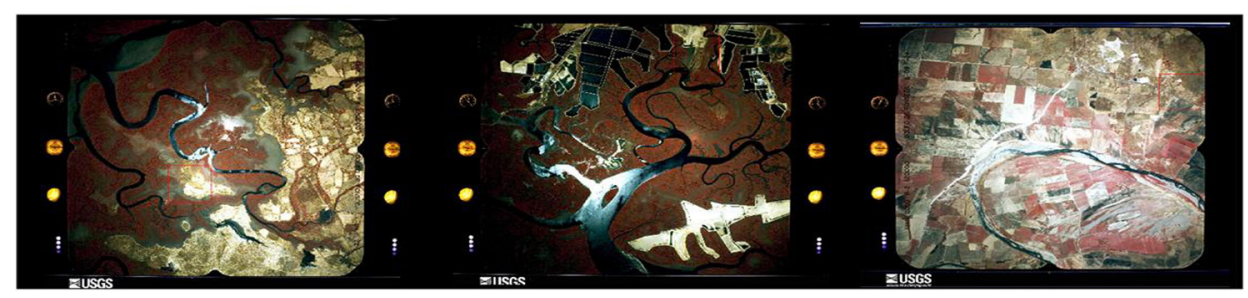

FIGURA 1. Foto área USGS de AT-5 Isla Potrerillos (izqda.), AT-6 Camaronera (centro) y AT-2 La Ola (dcha.)

Actualmente se dio cuenta de un posible sitio en la isla de Amapala (AT-4) en el golfo de Fonseca y la isla de Potrerillos (AT-5) en San Lorenzo, departamento de Valle. Así como sitios de arte rupestre con el símbolo aparente de Venus entre los diseños encontrados. También se dispone de información y muestras de un sitio que fue destruido por la construcción de una Camaronera (AT-6) en el departamento de Choluteca.

\subsection{Datos e imágenes de satélite}

Para el desarrollo de la investigación se ha utilizado cartografía de la zona sur de Honduras (departamentos de Choluteca y Valle). En concreto se ha dispuesto de las hojas cartográficas de base en escala 1:50.000, elaborada por el Instituto Geográfico Nacional (Dirección de Catastro y Geografía) y datos actualizados del sistema Nacional de Información Territorial (SINIT).

Se han utilizado datos, metadatos e imágenes en el período mencionado procedentes de los sensores espaciales ALI (Figura 2), TM y ETM+. El captador de 
imágenes ALI (Advanced Landlmager) es un sensor multiespectral del programa Earth Observation del USGS/NASA (United States Geological Survey/National Aeronautics and Space Administration). El sistema ALI, montado en el satélite EO-1, orbita a 705 kilómetros y captura imágenes pancromáticas y multiespectrales similares a las tomadas por lo satélites tipo LANDSAT. Adquiere 11 bandas espectrales de imagen desde el visible al infrarrojo medio, a las que se han agregado 3 bandas que cubren los $0.433 \mu \mathrm{m}$ a $0.453 \mu \mathrm{m}, 0.845 \mu \mathrm{m}$ a $0.890 \mu \mathrm{m}$, y $1.20 \mu \mathrm{m}$ a $1.30 \mu \mathrm{m}$. Su resolución espacial es de $20 \mathrm{~m}$ para las bandas multiespectrales y $10 \mathrm{~m}$ para la banda pancromática.

\section{FIGURA 2. Escena ALI en combinación RGB 7,4,2 (izqda.) y detalle de la Isla Amapala (AT-4)} con banda pancromática ALI fusionada con las multiespectrales.
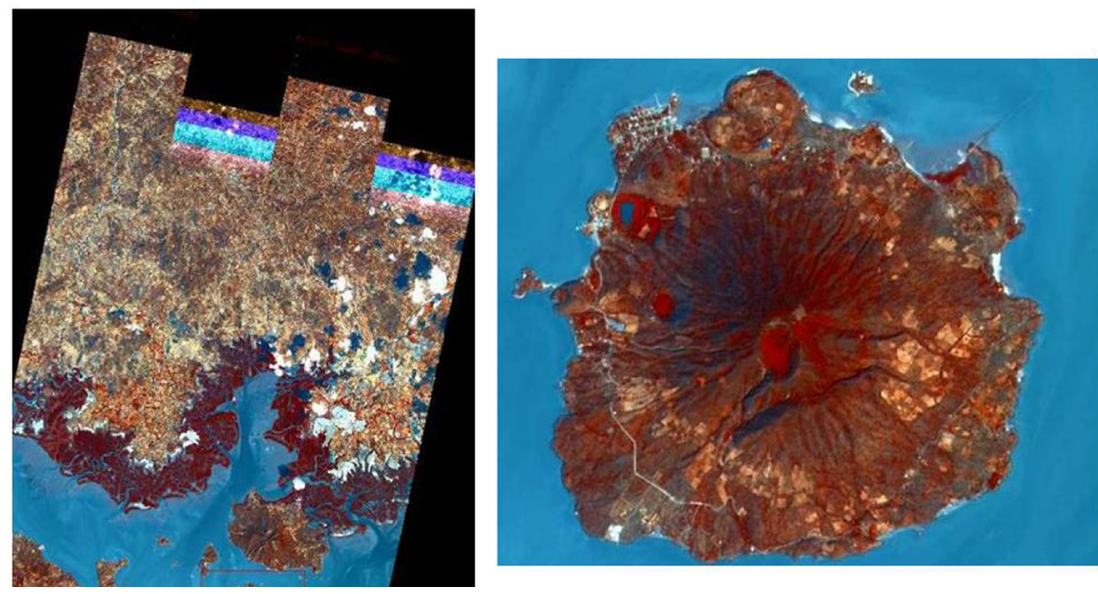

Asimismo, se han utilizado escenas del sensor ETM+ (Enhanced Thematic Mapper) que añade a las bandas ya disponibles en el TM (bandas multi espectrales de imagen desde el visible al infrarrojo térmico una resolución espacial de $30 \mathrm{~m}$ y $60 \mathrm{~m}$ ) un canal pancromático con resolución espacial de 15 metros. Su órbita se sitúa a $705 \mathrm{Km}$ de altitud, y sobrevuela la misma zona cada 16 días.

Los datos espaciales, así como fotografía aérea en niveles de gris y en color (Figura 1), se adquirieron desde el sitio web de EarthExplorer.

\section{MÉTODOS DE TELEDETECCIÓN EN EL ESTUDIO ARQUEOLÓGICO}

La investigación incorpora una fase de gabinete, para la que se han utilizado fundamentalmente datos espaciales, y diversas fases de campo diseñadas 
a efectos de reconocimiento sobre el terreno, muestreo, radiometría de campo y validación.

Se han aplicado técnicas de teledetección a partir de los datos mencionados, como son análisis exploratorios, clasificación digital de imagen, análisis espectral de firmas y análisis de anomalías espectrales del terreno. Los datos de los sensores ALI, TM y ETM+ han sido primeramente pre-procesados y co registradas todas las bandas. Ha sido necesario transformar las imágenes a una escala absoluta, tanto espacial como espectral, de tal manera que podamos referir las medidas extraídas a otras procedentes de los distintos sensores o tomadas en distintas fechas. El objetivo ha sido preparar el conjunto de los datos para correlacionar espacialmente los elementos de interés arqueológico (muros, superficies, estructuras, restos de origen orgánico etc) con parámetros biofísicos extraídos mediante técnicas de tratamiento de imagen.

Se han aplicado filtros de imagen de paso alto y de texturas (Figura 3, izqda.) y se han calculado índices entre bandas como análisis exploratorios previos. Con ello se pretende correlacionar patrones espectrales y bordes, así como parámetros del suelo y vegetación con la identificación de estructuras arqueológicas.

Figura 3. Detalle de imagen ALI de AT-5 sin fusión (izqda.) y fusionada (centro) en combinación RGB 7, 4, 2. Filtro de textura aplicado a imagen fusionada de AT-5, en combinación rgb para los canales $7,4,2$.
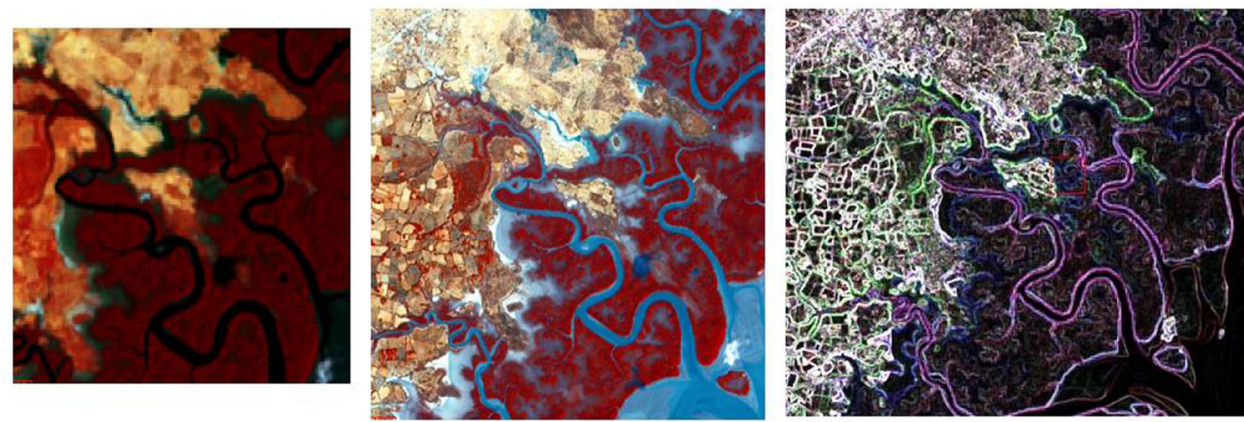

Se han calculado índices de vegetación y de suelo para el conjunto de las imágenes (Figura 4). Se han calculado tres índices de vegetación a partir de los valores de reflectancia de las imágenes multi espectrales. Se ha generado el NDVI (Rouse et al., 1974) para evaluar la estimación de la cubierta (IAF), y el cociente (Berni et al., 2010) entre el índice de reflectancia transformada por la absorción de la clorofila (TCARI) y el índice de vegetación del suelo ajustado optimizado (OSA$\mathrm{Vl})$. 


$$
N D V I=\frac{\rho_{\mu \mathrm{VIR}}-\rho_{\mu R}}{\rho_{\mu \mathrm{NIR}}-\rho_{\mu R}}
$$

donde $\rho_{\mu N \mathbb{R}}=$ reflectancia de banda del infrarrojo próximo,

$$
\rho_{\mu \ll}=\text { reflectancia de banda del rojo. }
$$

\section{TCARI / OSAVI}

$$
=3 \cdot\left[\left(\rho_{\mu 700}-\rho_{\mu 670}\right)-0.2 \cdot\left(\rho_{\mu 700}-\rho_{\mu 550}\right) \cdot\left(\rho_{\mu 700}-\rho_{\mu 670}\right)\right)(1+0.16) \cdot\left(\rho_{\mu 500}-\rho_{\mu 670}\right) /\left(\rho_{\mu 500}-\rho_{\mu 670}+0.16\right)
$$

donde $\rho_{\mu i}=$ reflectancia de la banda i.

Figura 4. Detalle de Choluteca TM 1999 rgb 3,4,1 (sup. izqda.) e índice TCARI/OSAVI (sup. dcha.); detalle del golfo de Fonseca TM 1999 rgb 3,4,1 (inf. izqda.) e índice TCARI/OSAVI (inf. dcha.); detalle de AT-5 en TCARI/OSAVI a partir de la imagen ALI de 2003 (dcha.).
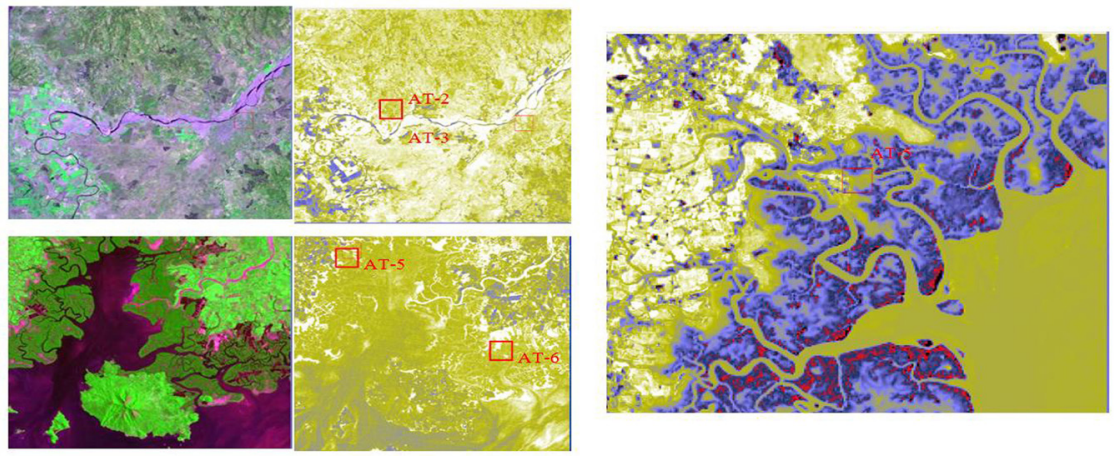

Un último paso en el análisis exploratorio ha consistido en aplicar fusión de imagen a las bandas multiespectrales con la banda pancromática mediante el algoritmo Imgfuse (Geomatica). Se han generado nuevas escenas de $10 \mathrm{~m}$ para ALI (Figura 3, centro) y 15 m para TM y ETM+ de resolución espacial, manteniendo la información espectral original, que han intervenido en el análisis de imagen subsiguiente.

Se ha aplicado al conjunto de las imágenes el algoritmo RX (Reed y Xaoli, 1996) admitido ampliamente como un estándar en la detección de anomalías espectrales. Las anomalías espectrales se han calculado primero para el conjunto de bandas multiespectrales fusionadas con la banda pancromática. Se ha aplicado una variación del método de cálculo de anomalías, incorporando los índices de 
vegetación y suelo como nuevas variables (Figura 5 , centro). Se ha observado cómo las anomalías espectrales están relacionadas con los parámetros de suelo y vegetación, influidos asimismo por la estación del año.
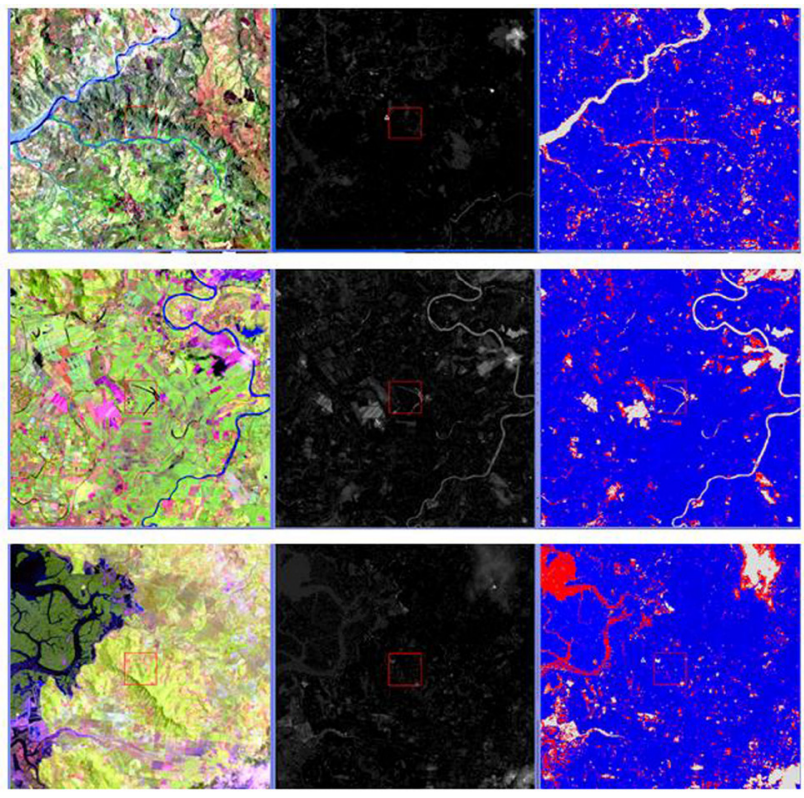

\section{DISCUSIÓN DE RESULTADOS Y VALIDACIÓN}

Los resultados obtenidos con el tratamiento de las imágenes espacial han permitido obtener posibles casos positivos de presencia de restos arqueológicos 0 antropológicos (Figura 6, Tabla 2) y generar una cartografía temática de cambios de cobertura del terreno en las fechas estudiadas.

No obstante, se ha realizado un exhaustivo reconocimiento de campo mediante sucesivas visitas, uno de los de cuyos objetos ha sido la recolección de información mediante entrevistas a reputados investigadores arqueólogos e historiadores. La documentación mediante expertos unida al reconocimiento a pie de terreno permite confirmar o desechar los casos extraídos del tratamiento de las imágenes como posible presencia de restos arqueológicos.

\subsection{Muestreos y verificación de campo}

Se realizaron dos giras durante los meses de febrero y abril de 2013, visitando los departamentos de Valle y Choluteca en el sur de Honduras. En ellas se 
ha realizado un reconocimiento de los emplazamientos a pie de terreno y se han georreferenciado mediante posicionamiento global GPS en modo autónomo, con 1 metro de precisión absoluta, suficiente para su contraste en las imágenes espaciales utilizadas.

Asimismo, se ha realizado una primera validación y archivo fotográfico de los sitios de investigación. Se encuestó a pobladores para obtener información local de los sitios de estudio. Se verificó posible clasificación arqueológica de sitios estudiados en un inicio (Tabla1).

Figura 6. Mapa generado a partir de mosaico TM en banda 5 con la localización de las áreas de interés (cuadrado azul) y posibles casos de existencia de restos arqueológicos/antropológicos (triángulo rojo)

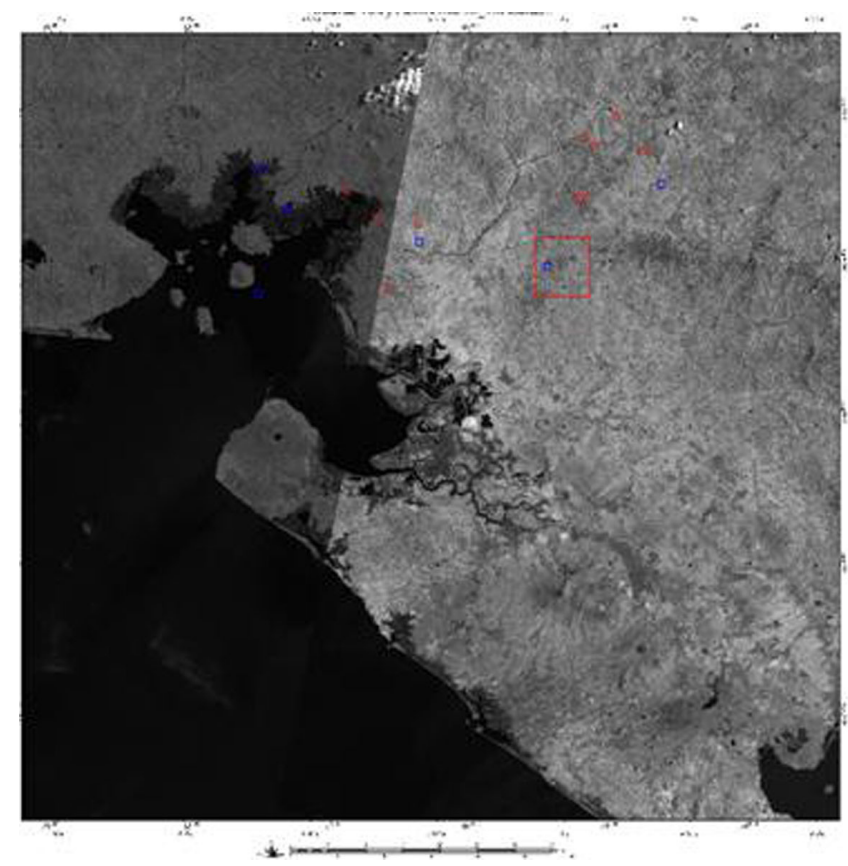

Tabla 2. Posibles casos positivos de presencia de restos arqueológicos extraídos del análisis de imagen 


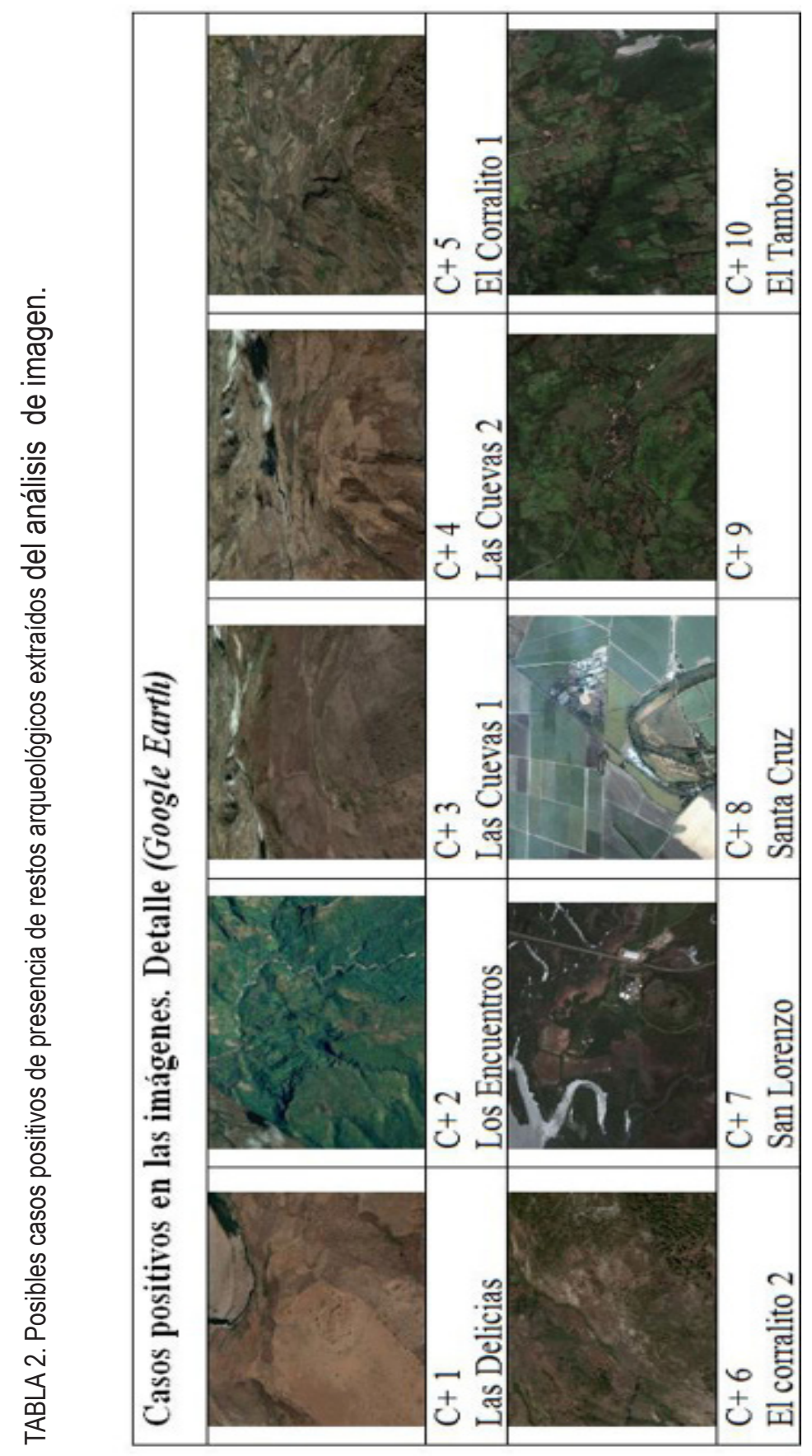




\subsection{Clasificación de sitios arqueológicos}

Uno de los objetivos globales de la investigación es realizar una clasificación contrastada de sitios arqueológicos presentes en el área de estudio. Veliz (2009) menciona que en el proyecto La Entrada (Nakamura et al., 1991), se tomaron en cuenta para la clasificación de los sitios arqueológicos los criterios de tamaño (1), ordenamiento arquitectónico (2), complejidad (3), extensión (4) y presunta función (5).

En base a ellos se desarrolla la clasificación arqueológica en 4 categorías que ha sido adoptada en la investigación:

- Categoría especial. Cementerios, estructuras sobre cerros, petroglifos, lugares de producción de cerámica y de lítica.

- Categoría 1. Artefactos dispersos en la superficie, sin estructuras presentes.

- Categoría 2. Una estructura aislada o agrupamientos de estructuras de menos de $2 \mathrm{~m}$ de altura. Algunos agrupamientos tienen patios, los que se supone son unidades habitacionales de campesinos.

- Categoría 3. Se definen por las siguientes características: (i) estructura más alta mide aproximadamente de 2 a $3.5 \mathrm{~m}$ de alto, (ii) casi todos tienen patios (o plazas), (iii) el tamaño de las estructuras aumenta, pero en comparación con las de Categoría 2, son bastante pequeñas y (iv) en algunos existen pisos de estuco, tiestos policromados y piedra tallada. El residente se supone haber sido alguien con cierto poder político local.

Teniendo en cuenta esta clasificación, se realizó un reconocimiento a pie de terreno de las siguientes áreas de interés (Tabla 3), contrastando al mismo tiempo el análisis de imagen: 
Tabla 3. Áreas de interés reconocidas a pie de terreno en febrero -abril de 2013

\begin{tabular}{|c|c|c|c|c|}
\hline Área & Nombre & Localización & Tipo de restos & $\begin{array}{l}\text { Clasificación } \\
\text { arqueológica }\end{array}$ \\
\hline $\begin{array}{l}\text { AT-1 } \\
\text { AT-5 }\end{array}$ & $\begin{array}{l}\text { Salineras- Isla } \\
\text { de Potrerillos }\end{array}$ & Valle & $\begin{array}{l}\text { Montículos, } \\
\text { tiestos, uso de } \\
\text { bivalvos y lítica }\end{array}$ & Categoría 2-3 \\
\hline AT-2 & La Ola & Choluteca & Se ubicó alterado & Sin categoría \\
\hline AT-3 & Colama & Choluteca & Montículos & Categoría 3 \\
\hline AT-4 & Isla Amapala & Golfo de Fonseca & $\begin{array}{l}\text { Restos de } \\
\text { cerámica }\end{array}$ & Categoría 2 \\
\hline AT-7 & Las Pintadas & Choluteca & Arte rupestre & $\begin{array}{c}\text { Categoría } \\
\text { especial }\end{array}$ \\
\hline AT-6 & Camaronera & Valle & Tiestos y lítica & Categoría 2 \\
\hline AT-8 & El Corpus & Choluteca & Colonial & \\
\hline AT-9 & El Mitre & Choluteca & $\begin{array}{c}\text { Cerámica y } \\
\text { muros }\end{array}$ & $\begin{array}{c}\text { Categoría } \\
\text { especial }\end{array}$ \\
\hline AT-10 & La Pintura & Choluteca & Arte rupestre & $\begin{array}{c}\text { Categoría } \\
\text { especial }\end{array}$ \\
\hline AT-11 & Los Calpules & Choluteca & $\begin{array}{l}\text { Cerámica y } \\
\text { montículos }\end{array}$ & Categoría 3 \\
\hline
\end{tabular}

AT-2. Hacienda La Ola departamento de Choluteca, Sitio con cerámica y asentamientos. Punto central, antigua casa principal de hacienda La Ola, ecosistema de bosque seco con intervención. Suelo con roca volcánica, metamórfica, y arcilloso. No evidencia arqueológica después de 50 años de primera investigación. (Stone, 1957).

AT-3 El sitio de Colama es una hacienda ubicada después del desvió al Papalote, por el cerro el Perico o entrando a la ciudad de Choluteca, desvió de tierra antes de la hacienda el Inglés.Se encontró evidencia de montículos diversos en una amplia zona, No se tuvo acceso directo a hallazgo por ser propiedad privada cercada con Caballos. El lugar aun esta conservado.

AT-1. Isla de Potrerillos, bahía de Chismuyo, departamento de Valle, sitio precolombino: Hoja 2656 li, bahía de Chismuyo. carretera Choluteca-Alianza, se toma desvió a El Aceituno, pasando campo de balompié hasta llegar a Pozo Sarco Cubulero, de aquí se llega a las salineras, se cruza el bosque de mangle a pie y se 
llega a isla. Aproximadamente recorrido de $5 \mathrm{~km}$. del desvío. Ecosistema de bosque de mangle. Se ubican 4 montículos, uno de los cuales es más grande, también una plataforma visible. Se encuentra material de tiestos monocromos, pedernal y piedras volcánicas como herramientas, además conchas de bivalvos en depósitos. Se puede decir que sitio está en buen estado de conservación. Hay indicios de saqueo y destrucción de particulares. Hay que caminar $0.5 \mathrm{~km}$. por bosque de manglar para llegar a sitio. El suelo es arenoso- arcilloso y salino (Figura 7).

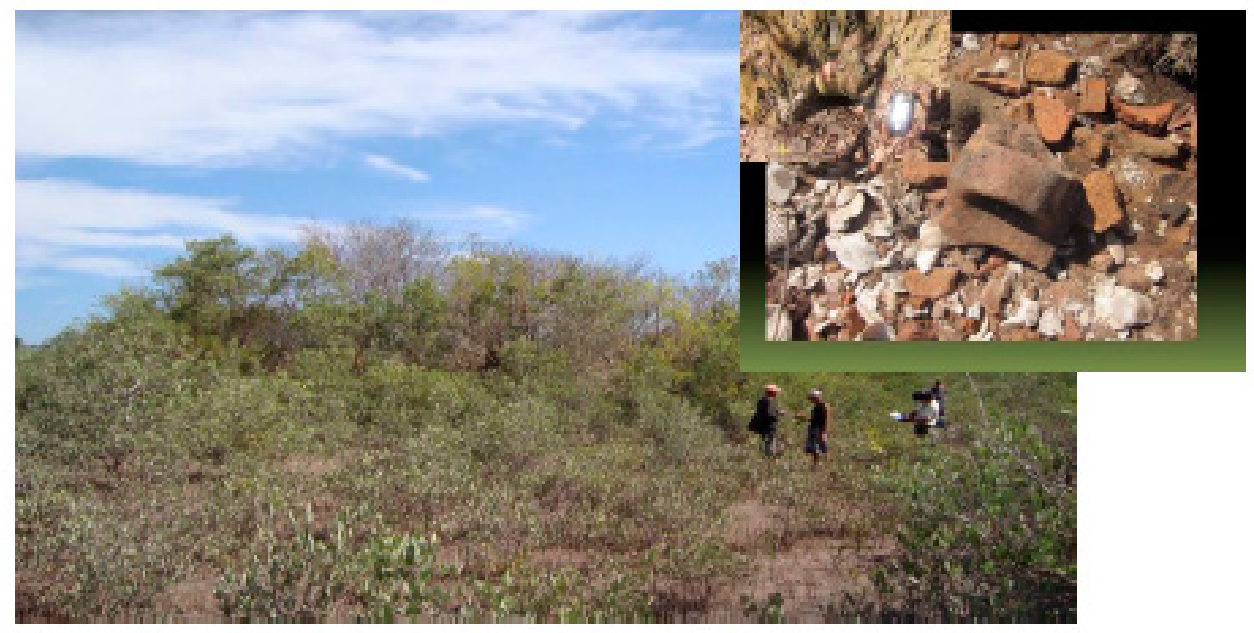

FIGURA 7. Isla Potrerillos, los montículos son visibles, Departamento de Valle.

AT-6. La Camaronera, Valle, sitio precolombino: Evidente destrucción. Zona intervenida para cultivo de camarón, con bosque de mangle. Se evidencia cerámica monocroma y piedra. El sitio está a orilla de un estero, de suelo arenoso. Se llega saliendo de la ciudad a Choluteca, se toma desvío a Coyolito, se le conoce al lugar como El Burro (Figura 8). 
Figura 8. La Camaronera, destrucción de montículo, Valle

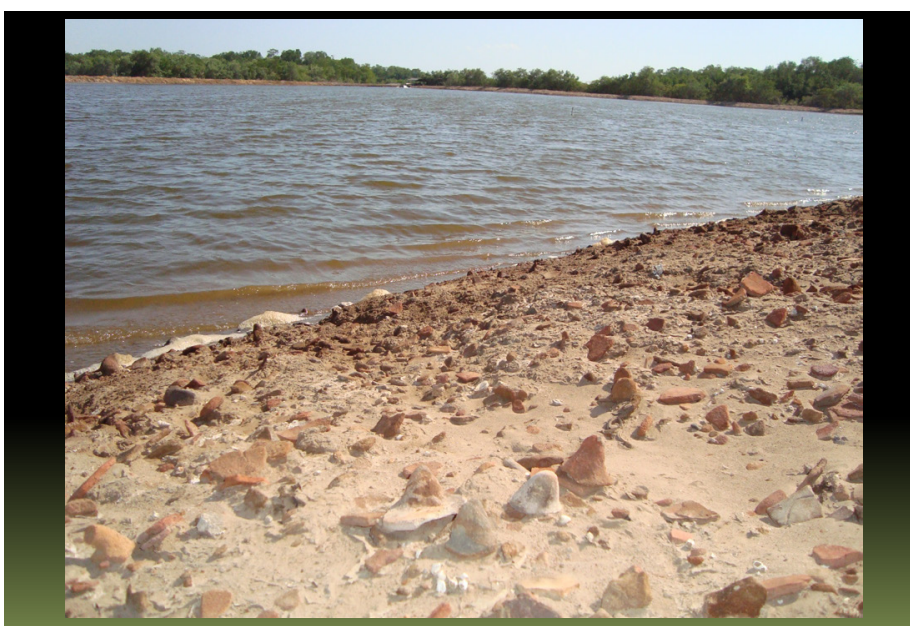

AT-4 Isla de Amapala ubicada en el golfo de Fonseca, se encontró evidencia de actividad volcánica en rocas de basalto y granito en el recorrido por toda la isla. Sólo un lugar denominado Tiguilote mostro evidencia arqueológica en un potrero cultivado, donde se encontró cerámica y rocas trabajadas como altares.

AT-8. El Corpus, Choluteca, Colonial. El Corpus es un antiguo pueblo minero en el sur de Honduras, con calles empedradas que data de 1584-1585, siendo famoso ante la corona española por la Mina de Clavo Rico (1585) que tenía pepitas de oro. Este pueblo está ubicado al este del departamento de Choluteca, aproximadamente a $20 \mathrm{~km}$ de distancia. Sus calles presentan evidencias de su pasado colonial.

AT-11 San Marcos de Colon próximo a la frontera con Nicaragua a $174 \mathrm{~km}$. de la ciudad de Choluteca, se ubicó un yacimiento arqueológico llamado "Cerro los Calpules" según la descripción de Doris Stone, a tres leguas de la ciudad de San Marcos de Colón y a tres leguas en dirección a la quebrada el Jocote. El lugar está a $15 \mathrm{~km}$ de la ciudad, entre bosque de pino, en una montaña y rodeado de algunas comunidades aisladas. Se ubicó una posible zona para estudio durante el camino. Carlos Ordóñez, poblador de los más antiguos del lugar, atestigua que en cafetales y bordos se han encontrado artefactos indígenas, y que en un sitio llamado Colón, en la carretera a Duyure se han encontrado artefactos.

Nosotros ubicamos el sitio conocido como Brisas de San Marcos, propiedad de una cooperativa de campesinos. Aquí se encuentra uno de los sitios mejor 
conservados, con cerámica, montículos, y plazas en peligro de destrucción. Este sitio es una prioridad para rescate y conservación con la participación de la comunitaria.

AT-7. Las pintadas de Concepción de María, departamento de Choluteca, arte rupestre. Tomando el desvío a Yusguare, después de pasar por el pueblo del Corpus-Choluteca, aproximadamente a $30 \mathrm{~km}$ desde el desvío. El lugar está ubicado antes de llegar al pueblo de Concepción de María-Choluteca. Bosque seco, intervenido por una población mediana, el suelo es arcilloso-calizo, con presencia de rocas volcánicas. En la casa de la señora Cándida Rosa Muñoz y la casa de la señora Kelyn Aguilar se ubican piedras grandes (Figura 10) de un metro y más de altura con diseños petroglifos geométricos y fitomorfos antiguos. Las rocas están siendo usadas para cerco de casas, algunas están partidas y presentan signos de contaminación.

Figura 9. Arte rupestre en Las Pintadas, Choluteca

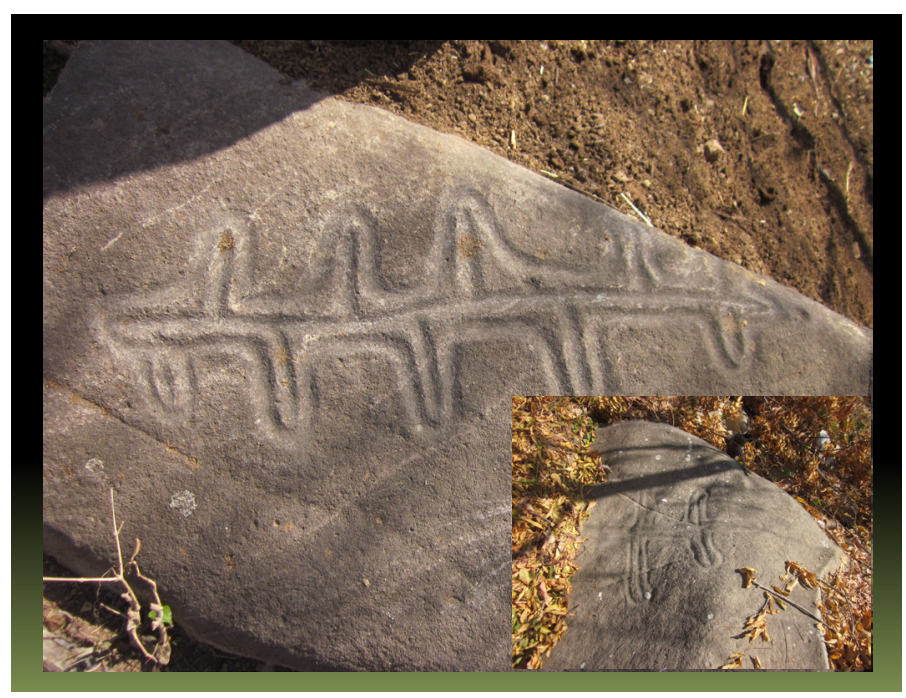

AT-8. Las Pinturas de Concepción de María, departamento de Choluteca, arte rupestre Tomando el desvío a Yusguare, después de pasar por el pueblo del Corpus-Choluteca. El lugar está ubicado antes de llegar al pueblo de Concepción de María-Choluteca. Bosque seco, intervenido por una población mediana, con presencia de rocas volcánicas. Una en especial con diseños petroglifos geométricos antiguos. Las rocas presentan signos de contaminación antropogénica. 
AT-9 El Mitre, Duyure. A través de recopilaciones bibliográficas se logro localizar este sitio arqueológico en lo alto de un cerro que sobresale en el paisaje, sin vegetación y erosionado. Este fue posiblemente un centro ritual, atestiguado por la cerámica dispuesta alrededor de estructuras de piedra como altares.

\section{CONCLUSIONES GENERALES}

El trabajo presentado supone una aproximación en la aplicación de técnicas y metodologías de la información geográfica en el valle de Choluteca y golfo de Fonseca. Se han expuesto las características y estrategias de adquisición de datos medidos en zonas del espectro reflectivo y emisivo de los sensores espaciales ALI, TM y ETM+. Esta experiencia ha permitido comprobar cómo diversas tecnologías de bajo coste permiten el registro y actualización de datos de arqueológicos. Se han estudiado 6 áreas de especial interés y se han extraído 10 posibles casos positivos de presencia de restos arqueológicos a partir del análisis espectral de imagen. Se ha comprobado cómo los sitios arqueológicos en la zona del manglar presentan especiales características para la investigación mediante teledetección, por su contraste entre la lámina de agua y los suelos.

Se ha iniciado el análisis exploratorio de los datos adquiridos entre 1990 y 2009 , focalizado en el estudio de la correlación espacial y patrones espectrales entre las superficies y materiales arqueológicos presentes en las áreas de interés. Para ello se han generado ficheros multifuente, resultando crítico para el análisis posterior de los datos el corregistro espacial preciso entre las distintas capas de información.

Finalmente, el trabajo presentado se enmarca dentro de la línea de investigación de teledetección y SIG aplicados al corredor mesoamericano, cuyos objetivos generales son el registro digital y la propuesta de metodología como apoyo al estudio arqueológico y soporte de para futuras prospecciones y acciones iniciales para la protección del patrimonio cultural hondureño en esta área.

\section{Líneas futuras de investigación}

Un línea de trabajo futura que se plantea, para la que serán necesarios estos primeros resultados geo referenciados con precisión, es el estudio de caminos óptimos y orientaciones astronómicas mediante SIG. 


\section{Agradecimientos}

Nuestro sincero agradecimiento a los coordinadores de la Maestría de Ordenamiento y Gestión del Territorio que imparten la Facultad de Ciencias Espaciales FACES/UNAH y la Universidad de Alcalá de Henares. A Rafael Corrales por su asesoramiento.

Agradecemos al Instituto Hondureño de Antropología e Historia por su apoyo y asesoramiento. Un agradecimiento especial a las personas que han colaborado, en particular Bertilo Amaya en logística y David Williams nuestro guía de campo, así como Luis Soto y Rodolfo Ferrufino de la Portuaria por su apoyo. A la señora Cándida Rosa Muñoz, a la señora Kelyn Aguilar y al señor Carlos Ordóñez, por su amabilidad y ayuda en la recopilación de información llevada a cabo sobre el terreno.

\section{BIBLIOGRAFÍA}

- ----- (s.f.) Ley de Patrimonio Cultural de la Nación Disponible en: http://www. ihah.hn/que_es/ley_patrimonio.htm [online] [consulta: 04-12-2012].

- Berni, J.A., Zarco-Tejada, P., Suárez, L and Fereres, E. (2010). "Thermal and narrowband multispectral remote sensing for vegetation monitoring from an Unmanned Aerial Vehicle." IEEE Transactions On Geoscience And Remote Sensing, Vol. 47, No. 3, March 2009.

- Burillo Mozota, Francisco, Severino Escolano Utrilla, Raúl López Romero y Enrique Ruiz

- Budría (2008) Roma versus Segeda: una propuesta sobre el camino hispano seguido por el cónsul Nobilior en el año 153 a.C. Fundación Segeda, Aragón Vivo.

- Farjas, M., Rejas, J.G., Mostza, T. and Zancajo, J. (2011). "Depening in the 3D modelling multisource analysis of a polychrome ceramic vessel through the integration of thermal and hyperspectral information". 39th annual international conference on Computer Applications and Quantitative Methods in Archaeology - CAA2011Beijing (China), 12th-16th, April 2011 
- Mostaza, T., Zancajo J.J. and Rejas, J.G. (2010). "Application of the New Techniques of Metric Documentation at Spatial Modeling of Archaeological Deposits" 38th CAA Congress, Granada (España), 16-20 abril 2010.

- Pineda Portillo, Noé (1997) Geografía de Honduras. Tercera Edición. Editorial Guaymuras, Tegucigalpa.

- Rejas, J.G., Pineda, M.C., Véliz, S.V., Burillo, F., Martínez, R., Marchamalo, M., Farjas, M. y Euraque, D.A. (2010). "Desarrollo en nuevas tecnologías para la protección y preservación del Patrimonio cultural y hábitats humanos en Honduras" IV Congreso Internacional sobre Patrimonio Cultural y Cooperación para el Desarrollo, Sevilla (España), 16-18 junio 2010.

- Rejas, J.G., Pineda, M.C., Véliz, S.V. y Bastarrica, A. (2010). "Perspectiva de la teledetección en prospección, protección y gestión del patrimonio cultural. Casos de estudio de Honduras". 1er Congreso Internacional sobre Ordenamiento del Territorio y Tecnologías de la Información Geográfica, Tegucigalpa (Honduras), 22-26 octubre.

- Rejas, J.G., Burillo, F., López, R., Cano, M.A., Sáiz, M.E., Farjas, M. (2009). "Integrating SAR data and hyperspectral analysis for the archaeological survey of the Segeda city, Spain." III 2009, International Conference on Remote Sensing in Archaeology, Space Time and Place 17-21 august, Tiruchirapalli (India).

- Rejas, J.G., Farjas, M., Burillo, F., López, R., Cano, M.A., Sáiz, M.E., Mostaza, T. and Zancajo J.J. (2008). "Comparative archaeometric analysis through 3d laser, short range photogrammetry, and hyperspectral remote sensing applied to the celtiberian city-state of Segeda". 37th International Symposium on Archaeometry, Siena (Italy), Mayo.

- Rejas Ayuga, J.G., Burillo Mozota, F., López, R. y Farjas Abadía, M. (2006). "Hyperspectral remote sensing application in the celtiberian city of Segeda". From Space to Place, 2nd International Conference on Remote Sensing Archaeology, Rome (Italy) 4-7 diciembre.

- Stone, Doris (1957). "The archaeology of central and southern Honduras". Papers of the Peabody Museum of Archaeology and Ethnology. Vol. 49, No. 3. 
Cambridge, Massachusetts.

- Veliz, Vito (1983). "Síntesis histórica de la arqueología en Honduras. Yaxkin, Vol. VI, Números 1 y 2: 1-8. Órgano de Divulgación del Instituto Hondureño de Antropología e Historia, Tegucigalpa.

- Veliz, Vito (2009-2011) Borrador del proyecto "Desarrollo en nuevas tecnologías para la protección y preservación del patrimonio cultural y hábitats humanos en Honduras" Tegucigalpa. 